\title{
Carta del prepósito general de la Compañía de Jesús
}

\section{Arturo Sosa Abascal S. I.}

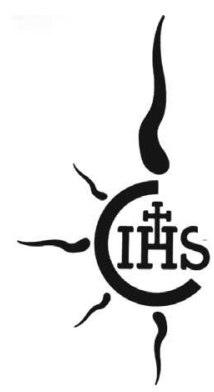

\section{CURIA GENERALIZIA DELLA COMPAGNIA DI GESÙ}

P. José Juan Romero Rodríguez, S.I.

Comunidad Portaceli de Sevilla

España.

\section{Querido P. Romero:}

Cuando la última Congregación General ha querido urgirnos a los jesuitas a seguir dedicando nuestras energías y nuestro entusiasmo al apostolado intelectual, usa palabras que seguramente ha recibido usted con alegría. "Nuestros centros de comunicación e investigación social dice - tienen que ser una ayuda para la formación de hombres y mujeres comprometidos con la reconciliación, que sean capaces de superar los obstáculos que a ella se oponen y proponer soluciones"1. Ha pasado mucho tiempo desde aquellos lejanos años $70^{\prime}$ cuando comenzaba usted a preparar clases y a inculcar en grupos de alumnos, ávidos de abrirse a la realidad compleja de un mundo en cambio, la importancia de la economía aplicada. Eran los primeros pasos para formar a hombres y mujeres en el entramado sutil que une indisolublemente $\mathrm{Fe}$ y Justicia; hombres y mujeres que se embarcasen activamente en la empresa, nada fácil, de fomentar el pensamiento social, emparentado así esas dos palabras, Fomento y Social, que constituyen el título de la Revista de la que fue usted director durante algunos años, y espíritu vivificador durante muchos más.

No es nuestro estilo de jesuitas usar demasiadas alabanzas entre compañeros, ni mucho menos agradecer cada uno de los servicios prestados a la causa del Reino, que compartimos como misión común con entusiasmo y entrega. Quiero, sin embargo, subrayar, P. Romero, que tuve ocasión de conocer en una Congregación General anterior su capacidad personal de entusiasmo y la amplitud universal que su mirada sabe dar a las cuestiones. He conocido su pasión por vivir la Misión como algo siempre compartido con otros. Sin duda han sido éstas algunas de las cualidades que han contribuido al talante franco para proponer vías de superación a los obstáculos, y para proponer soluciones positivas a los problemas, que caracterizan a la Revista que quiere ahora agradecer su larga presencia. 
No es nuestro estilo de jesuitas usar demasiadas alabanzas entre compañeros, ni mucho menos agradecer cada uno de los servicios prestados a la causa del Reino, que compartimos como misión común con entusiasmo y entrega. Quiero, sin embargo, subrayar, P. Romero, que tuve ocasión de conocer en una Congregación General anterior su capacidad personal de entusiasmo y la amplitud universal que su mirada sabe dar a las cuestiones. He conocido su pasión por vivir la Misión como algo siempre compartido con otros. Sin duda han sido éstas algunas de las cualidades que han contribuido al talante franco para proponer vías de superación a los obstáculos, y para proponer soluciones positivas a los problemas, que caracterizan a la Revista que quiere ahora agradecer su larga presencia.

Un jesuita tampoco se detiene demasiado celebrando el pasado. Mira con asombro la labor realizada hasta el momento, e interrumpe la tarea que tiene entre manos lo justo para volver la vista atrás con agradecimiento y seguir enseguida trabajando. Usted ha sido siempre consciente, de ello estoy seguro, que aquel entusiasmo suyo por crear un mundo en que la fe y la justicia caminasen de la mano, y que comenzó hace más de cuarenta años, habría de prolongarse y renovarse cada día en un futuro mayor que usted mismo. "El apostolado intelectual - termina el párrafo que citaba más arriba - debe ser fortalecido para cambiar nuestras culturas y nuestras sociedades". Es una tarea ambiciosa que empequeñece y subraya nuestra impotencia. Pero nosotros sabemos de quién nos hemos fiado, y quién es el último responsable de los resultados. Golpe a golpe, paso a paso, logramos que prosiga, en la mejor de las compañías, nuestra senda llena de ilusión y de esperanza.

Reciba, con mi aliento y mi apoyo incondicional, un saludo fraterno

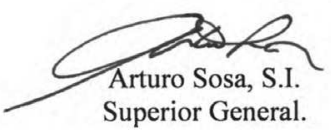

${ }^{1}$ CG 36. D. 1, n. 34.

Borgo Santo Spirito, 4-00193 Roma (Italia) | tel. (+39) 06698681 -fax (+39) 066868214 | curgen@sjcuria.org - www.sjweb.info 